\title{
In Favor of Establishment: Regulation of Chromatid Cohesion in Plants
}

\author{
Pablo Bolaños-Villegas ${ }^{\text {*t }}$, Kuntal De ${ }^{2 \dagger}$, Mónica Pradillo ${ }^{3}$, Desheng Liu $^{4}$ and \\ Christopher A. Makaroff4*
}

\begin{abstract}
' Laboratory of Molecular and Cell Biology, Fabio Baudrit Agricultural Research Station, University of Costa Rica, Alajuela, Costa Rica, ${ }^{2}$ Department of Radiation Oncology, James Cancer Hospital and Comprehensive Cancer Center, The Ohio State University Wexner School of Medicine, Columbus, OH, United States, ${ }^{3}$ Departamento de Genética, Facultad de Biología, Universidad Complutense de Madrid, Madrid, Spain, ${ }^{4}$ Hughes Laboratories, Department of Chemistry and Biochemistry, Miami University, Oxford, OH, United States
\end{abstract}

In eukaryotic organisms, the correct regulation of sister chromatid cohesion, whereby sister chromatids are paired and held together, is essential for accurate segregation of the sister chromatids and homologous chromosomes into daughter cells during mitosis and meiosis, respectively. Sister chromatid cohesion requires a cohesin complex comprised of structural maintenance of chromosome adenosine triphosphatases and accessory proteins that regulate the association of the complex with chromosomes or that are involved in the establishment or release of cohesion. The cohesin complex also plays important roles in the repair of DNA double-strand breaks, regulation of gene expression and chromosome condensation. In this review, we summarize progress in understanding cohesion dynamics in plants, with the aim of uncovering differences at specific stages. We also highlight dissimilarities between plants and other eukaryotes with respect to the key players involved in the achievement of cohesion, pointing out areas that require further study.

Keywords: cell division, CTF7, WAPL, PDS5, transposons, meiosis, recombination, DNA repair

\section{INTRODUCTION}

In eukaryotes, DNA faithfully duplicates during the $S$ phase of the cell cycle to produce sister chromatids. The newly duplicated sister chromatids are then tethered and held together by the cohesin complex until they segregate into new daughter cells (Uhlmann and Nasmyth, 1998). The cohesin complex is also involved in the repair of DNA double-strand breaks (DSBs), the regulation of gene expression and chromosome condensation (Guacci et al., 1997; Sjögren and Nasmyth, 2001; Onn et al., 2008; Nasmyth and Haering, 2009; Yuan et al., 2011; Lopez-Serra et al., 2013; Mehta et al., 2013; da Costa-Nunes et al., 2014).

In eukaryotic organisms, the cohesin core complex comprises four structural proteins: two structural maintenance of chromosome (SMC) adenosine triphosphatases (ATPases), SMC1 and SMC3; the $\alpha$-kleisin sister chromatid cohesion protein 1 (SCC1); and the SCC3 subunit. The interaction of cohesin with chromosomes is regulated by the genes PRECOCIOUS DISSOCIATION OF SISTERS 5 (PDS5) and WINGS APART-LIKE (WAPL). In animal cells, Sororin helps promote the stable association of cohesin with chromatin (Peters and Nishiyama, 2012). Tripartite rings are formed via the association of the SMC1-SMC3 heterodimer with SCC1 (Anderson et al., 2002; Haering et al., 2002). Different models have been proposed to explain the functional interaction of the complex 
with chromatin. The simplest model suggests that the ring entraps the two sister chromatids (Haering et al., 2008) (Figure 1). In other models, the interaction between different cohesin complexes can promote sister chromatid tethering (Eng et al., 2015). SCC1 also directly or indirectly associates with SCC3, PDS5, and WAPL (Haering et al., 2002).

Other SMC complexes exist, such as the condensin (SMC2/4) and SMC5/6 complexes, and their function is required in different contexts (Hirano, 2006). Condensins are multisubunit protein complexes that play a crucial role in the structural and functional organization of chromosomes (Ono et al., 2003). The majority of eukaryotes, including Drosophila possess two condensin complexes that participate in gene regulation, DNA repair and cell fate determination (Ono et al., 2003; Klebanow et al., 2016), while in Arabidopsis the condensin II complex is also important for conferring tolerance to excess soil Boron (Sakamoto et al., 2011). In addition to the SMC2/4 subunits, each complex may feature three non-SMC subunits, namely CAP-D2, CAP-G, and CAP-H for condensin I and CAP-D3, CAP-G2, and CAP-H2 for condensin II (Hirano, 2012). Arabidopsis CAP-D2 and CAP-D3 are required for pollen fertility and for preventing the association of centromeric repeats (Schubert et al., 2013). The eukaryotic SMC5/6 complex is primarily involved in DNA repair, replication fork stability, and possibly in the control of DNA topology (Verver et al., 2016). It consists of two SMC proteins and several non-SMC proteins (Andrews et al., 2005), which may interact with the ATPase head domain of SMC5 and SMC6 (Pebernard et al., 2004; Palecek et al., 2006). In Arabidopsis, the SMC5/SMC6 subunit AtMMS21 has been shown to regulate maintenance of root stem cells during embryogenesis and postembryonic stages (Xu et al., 2013). Given the evolutionary conservation of these complexes, it seems that their spatial organization and topology are very important to define their functionality (Gligoris and Löwe, 2016).

In this review, we summarize recent progress in understanding cohesion dynamics in plants, highlight differences at specific stages, key points of divergence between plant cohesin complexes and those from yeast and metazoans, and point out areas that require further study.

\section{THE CORE COHESIN COMPLEX}

In Arabidopsis, cohesion is mediated by the cohesin complex, consisting of two subunits of the SMC protein family, SMC1 and SMC3 (Liu et al., 2002). Both SMC1 and SMC3 are present in the Arabidopsis genome as single-copy genes (Liu et al., 2002). SMC1 and SMC3 are highly conserved among plant species and share the same characteristics: an N-terminal ATP binding domain, two large antiparallel coiled-coil regions separated by a hinge region, and a C-terminal DA box (Liu et al., 2002). The homozygous T-DNA knockouts of SMC1 (titan8-1 and titan8-2) and SMC3 (titan7-1 and titan7-2) show developmental defects in both embryo and endosperm that result in an early arrest in seed development (Liu et al., 2002).

Structural maintenance of chromosome 3 is found in both the cytoplasm and nucleus, bound to the nuclear matrix of somatic cells and in meiocytes (Lam et al., 2005). Specifically, it is localized from interphase to anaphase during mitosis, from premetiotic $\mathrm{G}_{2}$ to anaphase I during meiosis I, and in metaphase II centromeres during meiosis II (Figure 2). Strikingly, the protein is also present in the mitotic and meiotic spindle, so SMC3 may have additional roles in plant cells other than sister chromatid cohesion (Lam et al., 2005). No reports of Arabidopsis SMC1 have been published. In tomato, this protein, as well as SMC3, localizes along the axial elements (AEs), the precursors of the lateral elements (LEs) of the synaptonemal complex (SC), the tripartite structure that links homologous chromosomes in zygotene-pachytene meiocytes; but whether it is present in the cytoplasm and localizes to the spindle is unclear because studies were not conducted on whole cell mounts (Lhuissier et al., 2007).

Four orthologs of the kleisin subunit SCC1/radiation sensitive 21 (RAD21) have been detected in Arabidopsis and rice, and several SCC1/RAD21 genes are present in other plant species (Golubovskaya et al., 2006). During the first meiotic division, the mitotic kleisin subunit SCC1 is replaced by RECOMBINATION 8 (REC8), (Klein et al., 1999) which plays a role during meiosis that SCC1/RAD21 cannot support (Watanabe and Nurse, 1999). In maize, the ortholog of REC8 is ABSENCE OF FIRST DIVISION 1 (AFD1) (Golubovskaya et al., 2006). AFD1 is essential for the elongation of AEs and immunolocalization studies revealed that it localizes to the LEs of the SC. The AFD1 protein is also required for RAD51 distribution on the chromosomes and is also important for homologous chromosome pairing (Golubovskaya et al., 2006). In the rice genome, the putative REC8 ortholog is thought to be RAD21-4. RNA knock-down of this gene resulted in multiple aberrations during male meiosis, which included severe chromosome condensation, precocious segregation of homologous chromosomes and chromosome fragmentation (Zhang et al., 2006).

In the Arabidopsis genome, the REC8 ortholog is SYN1/DIF1 (Peirson et al., 1997; Bai et al., 1999; Bhatt et al., 1999; Cai et al., 2003). T-DNA syn1 mutants are sterile in both male and female gametophytes, but the protein is dispensable for somatic development; vegetative growth appears normal in the mutants (Bai et al., 1999; Bhatt et al., 1999; da CostaNunes et al., 2006). Male meiocytes show severe defects in sister chromatid cohesion, homologous chromosome pairing, and chromosome condensation that result in the fragmentation of chromosomes and formation of polyads (Peirson et al., 1997; Bai et al., 1999; Bhatt et al., 1999; Cai et al., 2003). Transmission electron microscopy of chromosomes in syn 1 meiocytes show short stretches of SC surrounded by condensed chromatin in late pachytene, which suggests that SYN1 is essential for SC formation (Zhao et al., 2006). In the syn1 mutant, the recombination machinery is partially functional since some recombination spots were seen in chromosomes (Zhao et al., 2006). Immunolocalization studies showed that SYN1 first appears on meiotic chromosomes beginning in late interphase. SYN1 antibody labels the developing chromosome axes beginning at early leptotene and lines the chromosome axes of paired chromosomes (Cai et al., 2003). A large portion of SYN1 dissociates from the chromosome arms during diplotene and diakinesis and by metaphase I the signal is only associated 


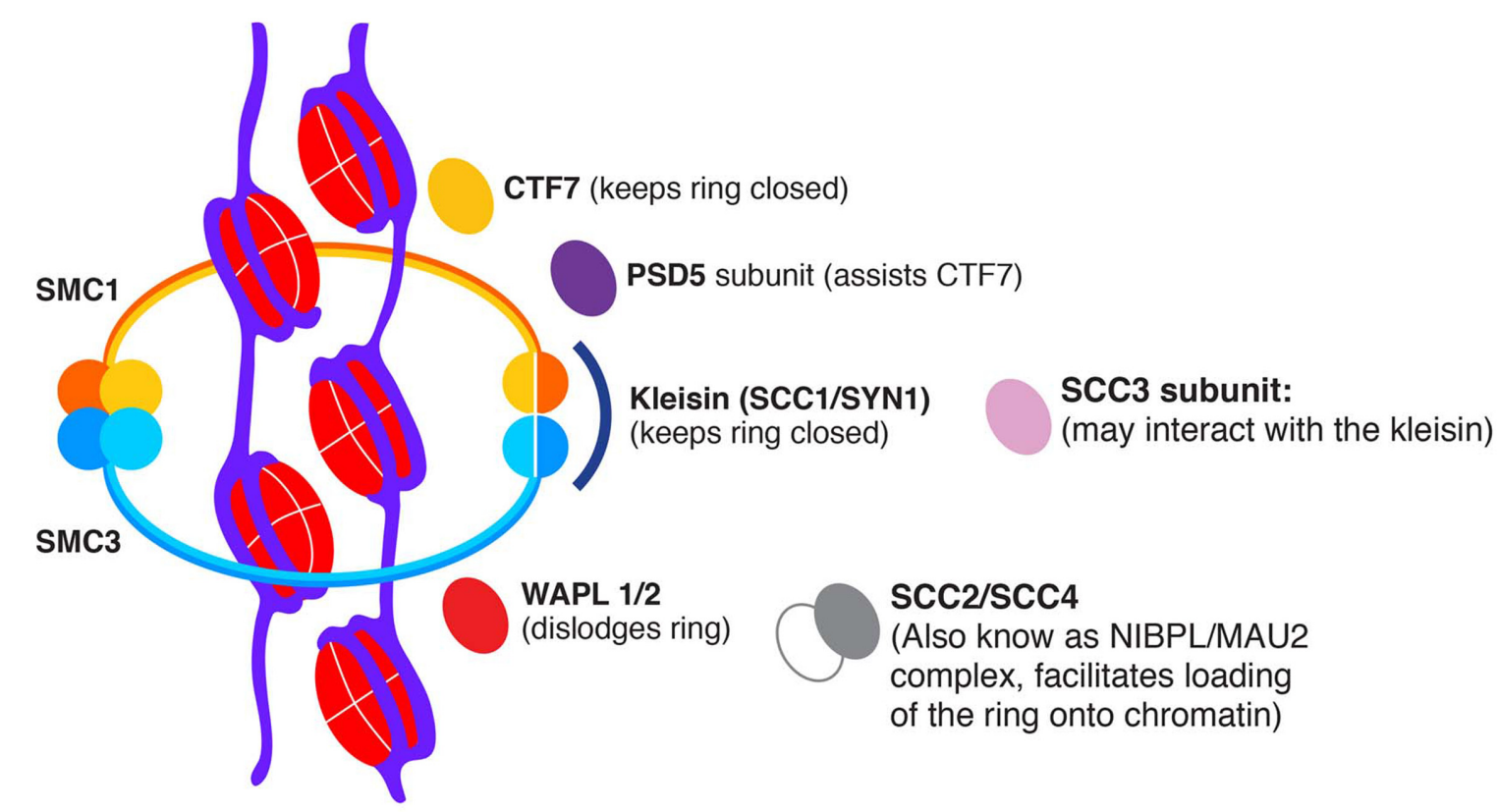

FIGURE 1 | Putative model of a plant cohesin ring. The presumptive Arabidopsis SMC1/SMC3 cohesin complex may tether sister chromatids, and its activity may be regulated positively by CTF7 and negatively by WAPL. Other regulators are the kleisin SCC1, the subunit SCC3, cohesin regulator PDS5 and SCC2/SCC4.

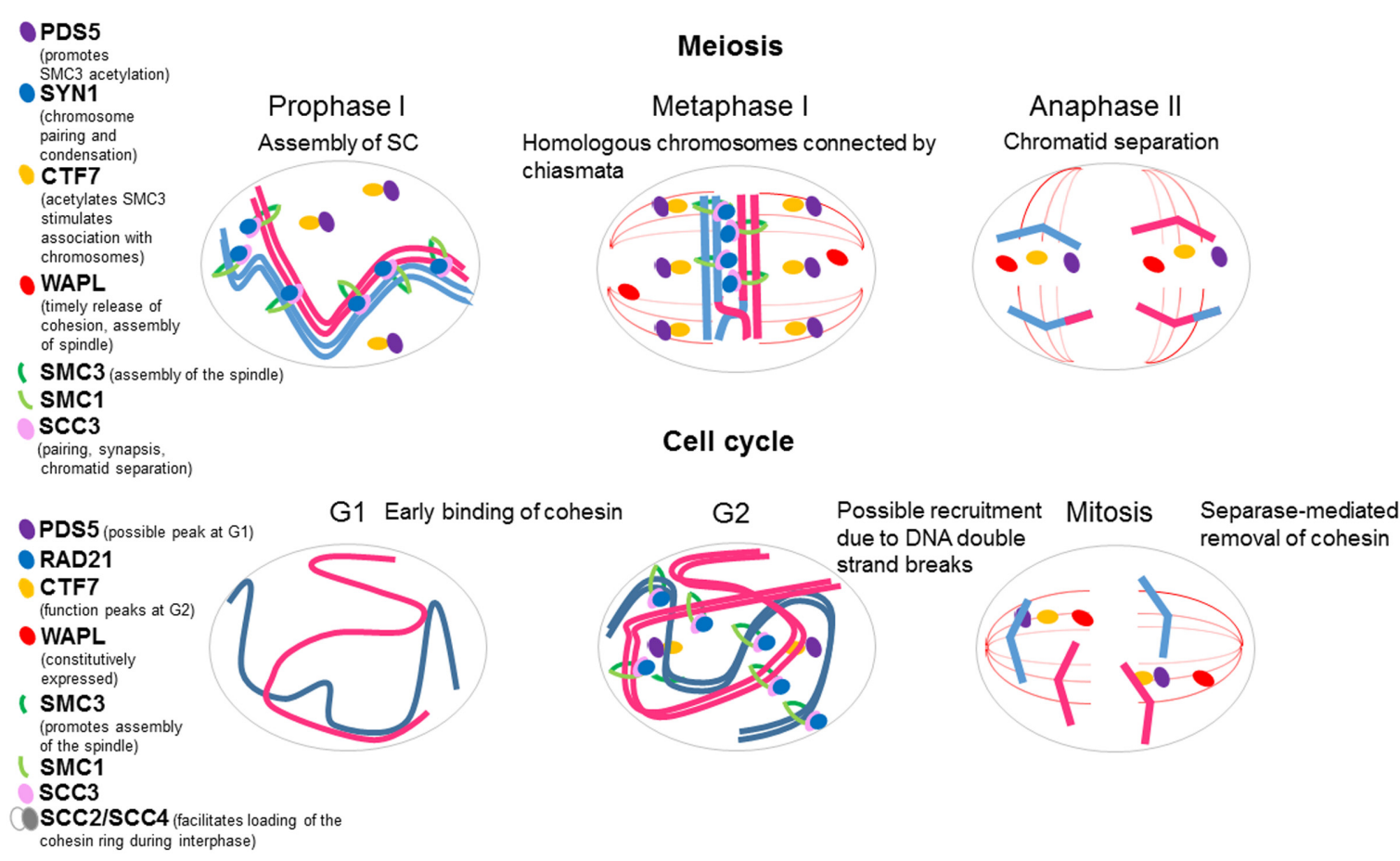

FIGURE 2 | Schematic representation of plant cohesin dynamics during mitosis and meiosis. Cohesin complexes contribute to meiotic chromosome dynamics, since they influence on pairing (alignment of homologous chromosomes), synaptonemal complex (SC) formation (intimate association of homologous chromosomes), and recombination (DNA exchanges, reciprocal or not, between homologous sequences). During prophase I, sister chromatid cohesion and reciprocal exchanges (crossovers, COs) maintain the homologous chromosomes connected as a bivalent after the SC is disassembled. Afterward, cohesion is removed in two steps: from chromosome arms during first meiotic division and from centromeres during second meiotic division (top). During mitosis, the complexes might be involved in replication and segregation of chromatids (bottom). 
with the centromeres. SYN1 signal is not typically detected at late metaphase I and early anaphase I. Similar to Arabidopsis SYN1, yeast REC8 dissociates from chromosome arms and by metaphase I the signal is localized only at centromeres (Klein et al., 1999; Watanabe and Nurse, 1999).

Arabidopsis has three other kleisin genes, SYN2/AtRAD21.1, SYN3/AtRAD21.2, and SYN4/AtRAD21.3, which are expressed throughout the plant (Dong et al., 2001; Jiang et al., 2007). SYN3 plays an important role in the nucleolus of both somatic and meiotic cells and is also indispensable for megagametogenesis (Jiang et al., 2007), while SYN2/AtRAD21.1 and SYN4/AtRAD21.3 play roles in DNA repair and may represent mitotic cohesins (Dong et al., 2001; da Costa-Nunes et al., 2006). Plants homozygous for mutations in AtRAD21.1 and AtRAD21.3 showed a decrease in sister chromatid alignment in somatic cells, suggesting that they may represent the mitotic cohesins (da Costa-Nunes et al., 2006). AtRAD21.1 has been shown to play a critical role in recovery after DNA damage during seed imbibition before germination (da Costa-Nunes et al., 2006), whereas AtRAD21.3 appears to play a role in somatic DNA DSB repair (da Costa-Nunes et al., 2014).

In contrast to mammals, SCC3 is present as a singlecopy gene in Arabidopsis. The corresponding protein is 1,098 amino acids long and exhibits $21 \%$ sequence identity and $40 \%$ sequence similarity to its yeast homolog. The transcript is expressed strongly in roots, mature leaves, buds, and plantlets (Cromer et al., 2013). In general, T-DNA insertional mutations of SCC3 result in embryo lethality; however, a weak allele, scc31 , hypothesized to express a truncated protein, confers both mitotic and meiotic defects and homozygous scc3-1 plants are dwarf and sterile (Chelysheva et al., 2005). Microscopy analysis revealed few dividing cells in root tips as compared with the wild type (WT), and male meiotic chromosomes showed defects in chromosome condensation, chromosome pairing and synapsis and presented early sister chromatid separation. During meiosis, SCC3 appears to localize at the chromosome axes until anaphase I, but during mitosis it is present throughout the entire cell cycle. Moreover, SYN1 binds normally to meiotic chromosomes in scc3-1 plants, but in syn1-1 plants, SCC3 localizes incorrectly to meiotic chromosome axes (Chelysheva et al., 2005). Whether the two proteins interact is still unknown.

\section{LOADING OF THE COHESIN COMPLEX}

Before DNA replication, SCC2 and SCC4 (also known as the NIBPL/MAU2 complex) mediate the recruitment of cohesin to chromosomes in Saccharomyces cerevisiae, Caenorhabditis elegans, and humans (Ciosk et al., 2000; Gillespie and Hirano, 2004; Watrin et al., 2006; Onn et al., 2008; Nasmyth and Haering, 2009). However, these proteins are not required to maintain cohesion after the completion of DNA replication. In fact, largescale mapping in several organisms such as $S$. cerevisiae and Schizosaccharomyces pombe has demonstrated that the cohesin complex and SCC2 bind non-randomly to chromosomes and that the respective binding loci may not overlap (Blat and Kleckner, 1999; Glynn et al., 2004; Lengronne et al., 2004; Weber et al., 2004; D’Ambrosio et al., 2008; Schmidt et al., 2009). Cohesin is enriched in regions around centromeres and at sites of convergent transcription, whereas SCC2 and SCC4 localize with transfer RNA genes (Glynn et al., 2004; D’Ambrosio et al., 2008). Cohesin may first associate with SCC2/SCC4, then relocate to sites of convergent transcription through the action of RNA polymerases (Lengronne et al., 2004; Hu et al., 2011; Fernius et al., 2013). The specific function of SCC2/SCC4 during loading of the cohesin complexes is unclear, but they may activate or prime the ATPase activity of SMC proteins, somehow allowing cohesin rings to entrap chromosomes (Haering et al., 2002; Arumugam et al., 2003; Gruber et al., 2003, 2006; Seitan et al., 2006). This behavior has been inferred from mutant SMC1 or SMC3 proteins that cannot hydrolyze ATP. These mutations lead to a phenotype that resembles that of $s c c 2$ or $s c c 4$ mutants in which cohesin rings are formed but fail to associate with chromosomes (Arumugam et al., 2003). Alternatively, it has been proposed that SCC2/SCC4 subunits might have a role in the remodeling of chromatin to facilitate the binding of cohesin (Hakimi et al., 2002; Huang et al., 2004; Ritchie et al., 2008).

In addition to SCC2/SCC4, other factors are required for the association of cohesin with chromosomes. For example, in Xenopus egg extracts, the CDC7/DRF1 kinase (DDK), a component of pre-replication complexes (pre-RCs), is essential for loading both SCC2/SCC4 and cohesin onto chromatin (Gillespie and Hirano, 2004; Takahashi et al., 2004, 2008; Ström et al., 2007). However, SCC2/SCC4 complexes have not been found associated with pre-RCs in yeast (Uhlmann and Nasmyth, 1998). In some instances, the kinetochore, transfer RNA transcription factors or proteins related to epigenetic mechanisms also participate in SCC2/SCC4-mediated loading of cohesin (Nonaka et al., 2002; Weber et al., 2004; D’Ambrosio et al., 2008). Nonetheless, although SCC2 and SCC4 are essential for cohesin loading, they are dispensable for cohesin maintenance and resolution during the $\mathrm{S}$ and $\mathrm{G}_{2}$ stages (Ciosk et al., 2000; Lengronne et al., 2006).

Functional characterization indicated that SCC2/SCC4 is essential for establishing sister chromatid cohesion in Arabidopsis (Sebastian et al., 2009). T-DNA insertional mutations in SCC2 and SCC4 lead to defects in embryo and endosperm development (Sebastian et al., 2009). Additionally, RNAi knockdown of SCC2 leads to defects during male and female meiosis, including chromosome clumping, chromosome fragmentation, loss of chromatid cohesion, SCC3 mis-distribution and defects in segregation (Sebastian et al., 2009). The predicted protein sequence of Arabidopsis SCC2 reveals a putative plant homeodomain (PHD) finger, a domain involved in chromatin organization and regulation of gene expression (Sebastian et al., 2009). Cytological analyses of T-DNA insertional lines Atscc2-2, Atscc2-3, Atscc4-1 and Atscc4-1 indicates that in these lines $25 \%$ of all embryos develop only up to the heart stage and show loss of bilateral symmetry, cell over-proliferation in the suspensor, and in the case of Atscc2-2, over-proliferation of the endosperm (Minina et al., 2017). In Atscc4-1 and Atssc2-2 analysis of the distribution of the auxin-response reporter DR5rev::3xVENUS-N7 indicates that most of the reporter is confined to the basal cells of the 
suspensor, which is the opposite to the wild type, suggesting the existence of: (a) alterations in the embryogenic potential of the suspensor in the mutants, and (b) a role for both SCC4 and SCC2 in embryonic cell fate determination (Minina et al., 2017). It was also found that SCC4 interacts stably with the N-terminus of SCC2 in planta and in baker's yeast, but this interaction is not required for proper localization of SCC4 to the plant nucleus in Atscc2-2 (Minina et al., 2017). The authors interpreted both this finding and the colocalization of SCC4 with mitotic kleisin RAD21.3/SYN4 during interphase as an indication that Arabidopsis SCC4 may play a special role in the determination of sites for cohesin loading on chromatin (Minina et al., 2017). Taken together all these results indicate that in Arabidopsis the SCC2 protein plays an important role during meiosis (Sebastian et al., 2009), while the SCC2/SCC4 complex regulates embryo and endosperm development with additional functions that are specific for each subunit (Minina et al., 2017).

\section{COHESION ESTABLISHMENT AND MAINTENANCE}

In yeast, sister chromatid cohesion is established during the $S$ phase of the cell cycle by the activity of Establishment of cohesion 1/Chromosome transmission fidelity 7 (Eco1/Ctf7) acetyltransferase soon after cohesins are recruited to chromosomes (Skibbens et al., 1999; Tóth et al., 1999; Onn et al., 2008; Nasmyth and Haering, 2009; Yuan et al., 2011). Eco1/Ctf7 acetylates lysine residues in the Smc3 subunit, close to its ATPase domain (K112 and K113). These residues are highly conserved among eukaryotes and are also acetylated in human cells by two proteins, establishment of sister chromatid cohesion $N$-acetyltransferase 1 (ESCO1) and ESCO2 (Hou and Zou, 2005; Zhang et al., 2008). Then the acetylated Smc3 protein interacts stably with Scc1 and counteracts the activity of the Rad61/Wpl1 (Wapl) complex, which is thought to promote the disassociation of cohesin from chromosomes (Rolef Ben-Shahar et al., 2008; Unal et al., 2008; Zhang et al., 2008; Rowland et al., 2009; Woo et al., 2009), possibly by interacting directly with the Ser/Thr phosphatase PP4, which has been shown to target kleisin Rad21 for dephosphorylation (Birot et al., 2017).

Vertebrates express an additional essential cohesion regulator called Sororin (Rankin et al., 2005). This protein associates with cohesin via acetylation and antagonizes WAPL by binding to PDS5 (Nishiyama et al., 2010). PDS5 also promotes SMC3 acetylation (Vaur et al., 2012; Chan et al., 2013). Hence, it integrates an anti-establishment action (by WAPL) with its requirement for cohesion maintenance during the cell cycle progression (Schmitz et al., 2007; Nishiyama et al., 2010). The Arabidopsis genome contains five putative PDS5 homologs that share similarity with fungal and mammal sequences (Mercier et al., 2001; Pradillo et al., 2015). Compromised expression of several PDS5 genes leads to a significant reduction in seed production (Pradillo et al., 2015). Depletion of PDS5 proteins alters only slightly meiotic division but alters DNA repair by homologous recombination (HR) (Pradillo et al., 2015).
The establishment of cohesion occurs concomitantly with DNA replication (Uhlmann and Nasmyth, 1998). In addition to Eco1 acetyltransferase, other proteins, related to DNA replication, contribute to the establishment of the SCC. In yeast, Eco1/Ctf7 interacts with DNA replication factors such as proliferating cell nuclear antigen (PCNA, a DNA polymerase processivity factor) (Moldovan et al., 2006), replication factor C (a component of the clamp loader replication factor C) (Mayer et al., 2001), the DNA helix itself (Mayer et al., 2004), and various clamp loader subunits (Petronczki et al., 2004). Inactivation or mutations in Eco1/Ctf7 lead to defects such as chromosome mis-organization, mis-distribution of the cohesin complex and activation of cell cycle checkpoints (Skibbens et al., 1999; Tóth et al., 1999; Milutinovich et al., 2007). Deletions or mutations in Rad61/Wpl1, Pds5, Smc3 and Scc3 may suppress the effect of deletions in Eco1/Ctf7, which suggests a degree of functional redundancy in the activity of Eco1/Ctf7 or that other factors can modify cohesin to counteract the activity of Eco1/Ctf7 during the establishment of cohesion (Warren et al., 2004; Rolef Ben-Shahar et al., 2008; Rowland et al., 2009; Sutani et al., 2009; Chen et al., 2012).

Experimental evidence indicates that Arabidopsis ECO1/CTF7 can functionally replace its yeast ortholog (Jiang et al., 2010; Bolaños-Villegas et al., 2013; Singh et al., 2013). Arabidopsis CTF7 lacks an N-terminal extension common in other organisms but features a PCNA-interacting protein (PIP) box, a $\mathrm{C}_{2} \mathrm{H}_{2}$ zinc finger motif and an acetyltransferase domain (Jiang et al., 2010). Similar to other species, Arabidopsis CTF7 appears to have a dosage-dependent function. Heterozygous ctf7 plants exhibit defects in the development of female gametophytes, with no obvious defects in microsporogenesis. Vegetative growth is normal in these plants, but siliques contain fewer seeds than in WT plants and many show embryonic developmental defects. Inactivation of Arabidopsis CTF7 typically results in embryo lethality; however, homozygous ctf7 mutant plants, which are completely sterile, can be obtained at very low frequencies. These plants show a more drastic phenotype: they are dwarf and feature fewer epidermal cells per area. Also, cell cycle progression is defective (Bolaños-Villegas et al., 2013). Furthermore, ctf7 mutant plants exhibit a severe loss of sister chromatid cohesion during mitosis and meiosis as well as significantly reduced localization of cohesin onto chromosomes (Bolaños-Villegas et al., 2013). The absence of ECO1/CTF7 impairs cytosine methylation, especially CG methylation (Bolaños-Villegas and Jauh, 2015). In addition, genes involved in HR are upregulated, which suggests defects in DNA repair (Bolaños-Villegas et al., 2013). Similar phenotypes were observed in plants transformed with a dexamethasone-inducible CTF7-RNAi construct. Finally, overexpression of the CTF7 genomic sequence leads to ovule arrest at female gametophyte 1 stage (Liu and Makaroff, 2015).

Extensive studies in different species have shown that WAPL controls mitotic sister chromatid cohesion and takes part in the removal of cohesin (Kueng et al., 2006). In Drosophila, WAPL has an important role in the organization of heterochromatin (Verni et al., 2000). The WAPL genomic sequence features a conserved C-terminus that may be a determinant of cohesin and a divergent $\mathrm{N}$-terminal domain that in humans contains a PDS5 
binding domain (Chatterjee et al., 2013; Ouyang et al., 2013). Although the effect of inactivation of WAPL during mitosis has been studied in several organisms (Cunningham et al., 2012; Chatterjee et al., 2013; Ouyang et al., 2013), much less is known about its role during meiosis.

The Arabidopsis genome contains two WAPL genes that appear to have a significant role in the removal of cohesin in the prophase (De et al., 2014). Arabidopsis plants homozygous for either of the wapl mutations have no obvious phenotype, but double homozygous plants show reduced fertility and severe defects in male meiosis, including defective organization of heterochromatin regions during prophase I, altered pairing of homologous chromosomes and delayed cohesin release during the first meiotic division. Assembly of the meiotic spindle is also severely impaired in double mutants. These problems may lead to the formation of chromosome bridges, broken chromosomes, uneven segregation of chromosomes and aneuploid gametes (De et al., 2014). In contrast, cohesin complexes appear to be removed normally in somatic cells (De et al., 2014). Hence, Arabidopsis WAPL genes may play a critical role during meiosis, and mechanisms involved in the removal of cohesin during prophase may vary between mitosis and meiosis in plants. Additionally, inactivation of the two Arabidopsis WAPL genes can suppress the lethal phenotype produced by the lack of CTF7 (De et al., 2016) and allows for normal vegetative growth and production of a reduced number of viable seeds (De et al., 2016). Immunolocalization of SYN1 in meiocytes confirmed that the release of cohesin during diakinesis is recovered in wapl1 wapl2 ctf7 triple homozygous mutant plants (De et al., 2016). However, comet assay experiments in vegetative tissues revealed that both WAPL1/2 and ECO1/CTF7 are important for the repair of DNA DSBs during the cell cycle in Arabidopsis (De et al., 2016). In addition, flow cytometry revealed a high level of aneuploidy in vegetative tissues of the triple mutant (De et al., 2016). All these results demonstrate that WAPL1/2 is important for the timely release of cohesion during meiosis and that inactivation of WAPL1/2 most-likely abrogates the requirement for SMC3 acetylation by CTF7 during mitosis (De et al., 2016). These plants are still able to develop and reproduce, which suggests the presence of an alternative cohesion pathway that awaits proper identification and functional characterization.

The Arabidopsis SMC-like gene SWITCH (SWI1), also known as DYAD, also plays a role in meiotic chromosome structure, maintenance and cohesion. The name is due to its function as a master controller of the switch from mitosis to meiosis (Mercier et al., 2001; Schubert, 2009). The corresponding mutant exhibits 10 univalents (instead of 5 bivalents) at the end of prophase I. Subsequently, chromatids lose their cohesion and their appear individually at metaphase I (Mercier et al., 2001, 2003). SWI1 is a plant-specific gene that has been characterized in several species. The maize homolog is AMEIOTIC1 (AM1). In am1 mutants premeiotic cells undergo mitosis instead of meiosis and meioticspecific cohesins are not installed on chromosomes (Pawlowski et al., 2009). In rice, OsAM1 is required for meiotic progression and the mutant fails to load OsREC8 on chromosome axes (Che et al., 2011).
Cohesion establishment and maintenance is also controlled by several posttranslational modifications. In addition to the acetylation mentioned previously, phosphorylation and SUMOylation play an essential role during cohesion establishment. Indeed, cohesin SUMOylation is indispensable for the entrapment of sister chromatids (Almedawar et al., 2012). In this sense, SUMO accumulates at DNA damage sites in $\mathrm{S} / \mathrm{G}_{2}$-phase human cells in a cohesin-dependent manner. This modification affects SCC1 and promotes DNA repair by sister chromatid exchange by antagonizing WAPL (Wu et al., 2012).

\section{COHESIN DISSOCIATION}

During cell division, cohesin needs to be removed for segregation of sister chromatids. The dissociation of cohesin is tightly regulated and takes place during two phases that involve different factors (Sumara et al., 2000; Waizenegger et al., 2000; Peters and Nishiyama, 2012). During the mitotic prophase and prometaphase stages, most cohesins are removed from chromosome arms, but those at the centromere stay. However, shortly before the onset of mitotic anaphase, all remaining chromosome-bound cohesin (mainly at centromeres) is removed when SCC1 is cleaved by Separase (Uhlmann et al., 1999; Sumara et al., 2000; Tomonaga et al., 2000; Waizenegger et al., 2000; Losada et al., 2002).

In vertebrates, Sororin is targeted for phosphorylation by cyclin-dependent kinase 1 (CDK1)/Cyclin B, which facilitates the action of PDS5-WAPL. This complex takes part in the release of cohesin from the chromosome arms (Schmitz et al., 2007; Nishiyama et al., 2010). The fraction of cohesin that remains at centromeres is protected by Shugoshin 1 protein (SGO1), which mediates the recruitment of Phosphatase 2A to protect cohesin against phosphorylation and hinder its release (Kitajima et al., 2004; Tang et al., 2006; Rivera and Losada, 2009). Other proteins such as Haspin (a histone H3 kinase) and Prohibitin 2 have been found involved in the protection of cohesion at centromeres (Dai et al., 2006).

The bi-orientation of chromosomes at metaphase is possible because cohesin is preserved at centromeres. Before metaphase, the anaphase-promoting complex (APC/C) remains inactive and Separase is inhibited by Securin and Cyclin B (Stemmann et al., 2001; Toyoda et al., 2002; Musacchio and Salmon, 2007). This pathway is regulated by the spindle assembly checkpoint (SAC). At the onset of anaphase, the SAC is disrupted and APC/C becomes active and targets Securin and Cyclin B for ubiquitylation and destruction (Uhlmann et al., 1999; Hauf et al., 2001; Musacchio and Salmon, 2007). Free from its inhibitors, Separase is released and activated (Nasmyth, 2000). At the same time, SGO1 is released from the centromere and SCC1 is phosphorylated. Separase then proceeds to cleave SCC1 and remove cohesin from sister chromatids (Nasmyth, 2000; Hauf et al., 2001). Finally, SMC3 is deacetylated by the histone lysine deacetylase 1 for reuse in the next cycle (Rivera and Losada, 2010).

During meiosis, cleavage along chromosome arms is pivotal for disjunction of homologous chromosomes at anaphase I, but 
it must not occur at centromeres, because cohesion of sister chromatids is indispensable for their correct bi-orientation at metaphase II (Bai et al., 1999). REC8, and other meiotic-specific factors such as SMC1 $\beta$ (SMC1) or Stromal Antigen 3 (SCC3) work in concert to protect centromeric cohesion during anaphase I and interkinesis (Dong et al., 2001; Prieto et al., 2001; Revenkova et al., 2001).

In Arabidopsis, the protection of meiotic centromeric cohesion depends on several proteins including SGO1 and SGO2, which are required at anaphase I, and PATRONUS 1 (PANS1), which is required at interkinesis and meiosis II and is presumably targeted by the APC/C complex (Cromer et al., 2013; Zamariola et al., 2013). In sgo1 sgo2 double mutant plants, immunolabeling for REC8/SYN1 suggested that this protein is not present at metaphase II (Cromer et al., 2013). The pans1 mutant features up to 10 single chromatids at each metaphase II plate and no REC8/SYN1 signal at metaphase II in chromatids (Cromer et al., 2013). PANS1 may protect REC8 or may inhibit cohesin release by WAPL inactivation (Cromer et al., 2013; Zamariola et al., 2013).

The predicted Arabidopsis Separase protein (extra spindle pole bodies 1, ESP1) is significantly longer than the corresponding proteins from yeast, worm, and fly, but is similar to the mammalian protein (Liu and Makaroff, 2006). ESP1 proteins from different organisms show high similarity in the C-terminus, which features a C-50 peptidase domain (Liu and Makaroff, 2006). The ESP1 peptidase domain shares approximately $20 \%$ sequence identity with the mammalian enzyme. However, the Arabidopsis ESP1 peptidase domain is considerably longer than those found in other organisms (700 vs. 400-470 amino acids) (Liu and Makaroff, 2006). Moreover, this domain consists of a predicted $2 \mathrm{Fe}-2 \mathrm{~S}$-Ferredoxin domain that is not present in other organisms. ESP1 in Arabidopsis contains an EF-hand/calcium-binding domain, which is also present in budding yeast, where it is important for initiation or maintenance of its association with the spindle (Jensen et al., 2001; Liu and Makaroff, 2006). The calcium-binding domain may have the same function in plants, but this has not yet been proven. Analysis of T-DNA insertional mutants suggests that ESP1 is an essential gene in that no homozygous plants from two different alleles could be obtained (Liu and Makaroff, 2006). Moreover 25\% of the seeds from heterozygous plants for the T-DNA insertions showed enlarged endosperm nuclei and nucleoli, a failure of the endosperm to cellularize, and embryo arrest at the globular stage, indicating that the protein is essential for embryo development (Liu and Makaroff, 2006). The radially swollen 4 ( $r s w 4)$ mutant is a temperature-sensitive line that contains a mis-sense mutation in ESP1 (Wu et al., 2010); replicated chromosomes fail to disjoin in roots. In addition, the roots of $r s w 4$ accumulate high levels of the mitotic-specific Cyclin $\mathrm{B} 1$ and show disorganized cortical microtubules. However, how inactivation of ESP1 specifically affects Cyclin B1 remains to be determined (Liu and Makaroff, 2006).

The role of ESP1 in Arabidopsis mitosis and meiosis has also been investigated by means of an RNAi construct driven by the $35 \mathrm{~S}$ and meiotic-specific DMC1 promoters (Yang et al., 2009). The inability to recover RNAi plants containing the
$35 S$ promoter suggested that ESP1 is an essential gene during mitosis. RNAi plants containing the DMC1 promoter showed entangled and stretched chromosomes during anaphases I and II (Yang et al., 2009). In addition, chromosome bridges and DNA fragmentation were observed, which suggested that ESP1 is an essential gene for HR as well as chromosome segregation during both meiotic divisions (Liu and Makaroff, 2006; Yang et al., 2009). SYN1 and SMC3 signals persisted along the chromosome arms and the centromeres throughout meiosis in DMC1-ESP1RNAi plants. ESP1 RNAi knockdown during meiosis induced non-homologous association of centromeres, disruption of the radial microtubule system after telophase II, and disruption of the nuclear cytoplasm, which resulted in multinucleate microspores (Yang et al., 2009). Thus, ESP1 appears to function beyond the removal of cohesin in plant cells. Despite the importance of ESP1, little is known about the mechanism of its regulation in plants (Yang et al., 2009). Analysis of plant genomes has failed to identify a putative plant homolog of Securin, and no experimental work has been conducted on the activation of the Separase pathway.

\section{ROLE OF COHESIN IN REPAIR OF DSBS}

Cohesin is important for postreplicative repair of DSBs in both mitosis and meiosis (Klein et al., 1999; Cortés-Ledesma and Aguilera, 2006). The essential function of cohesin in DNA repair is to allow a DSB on one sister to be repaired using the undamaged sister as a template. Thus, it brings the two sister chromatids into close proximity to facilitate the repair by HR. In budding yeast, cohesin is removed from the chromatin at DSB sites to promote DSB resection and repair (McAleenan et al., 2013).

As discussed above, SYN2/AtRAD21.1 and SYN4/AtRAD21.3 have been shown to play roles in DNA repair (da Costa-Nunes et al., 2006, 2014). Further, results from the characterization of ctf7 and wapl1 wapl2 ctf7 single and triple mutants suggested that the failure to establish and regulate cohesion leads to the expression of genes involved in HR and the establishment of cohesion, including ATM, BRCA1, RAD51, PARP2, SMC5, $S M C 6 B$, and TOPOII- $\alpha$ in vegetative tissues (Bolaños-Villegas et al., 2013; De et al., 2016). The basis for these changes in gene expression is not well understood and whether alternate errorprone DNA repair mechanisms such as non-homologous end joining (NHEJ) are activated is unclear. In this context, it is worth mentioning that in human cells the cohesin complex contributes to the protection of distinct double-strand ends in the NHEJ DNA repair pathway, helping to avoid genome rearrangements in $S / G_{2}$ phases (Gelot et al., 2016). It has been also demonstrated that the interaction between BREAST CANCER 2 (BRCA2) and cohesin via PDS5 is important for HR (Brough et al., 2012). In Arabidopsis, PDS5 genes are overexpressed upon exposure to $\gamma$-rays. Furthermore, the absence of PDS5 proteins causes hypersensitivity to DNA damaging agents and severely reduced $\mathrm{HR}$, which is probably related to reduced expression of SMC6 genes (Pradillo et al., 2015). The Arabidopsis SMC5/SMC6 complex meliorates sister chromatid alignment after DNA damage, allowing DNA repair by HR (Mengiste et al., 1999; 
Watanabe et al., 2009). Conversely, the reduced repair efficiency by HR in $s m c 6 b$ mutants may facilitate gene editing (Qi et al., 2013). It has been proposed that cohesin and SMC5/SMC6 have partially overlapping functions and can complement one another if necessary (Tapia-Alveal et al., 2014).

Beyond its function in DNA segregation and repair, cohesin influences other important biological processes such as the regulation of gene expression, duplication of centrosomes and spindle polar bodies, and chromosome condensation (Mehta et al., 2013). In meiosis, cohesin complexes are also important for repairing DSBs. Unlike mitosis, during meiosis the formation of DSBs is programmed and most of them are repaired using non-sister chromatids as templates. Meiotic cohesin complexes also influence chromosome organization to ensure proper chromosome pairing, synapsis, and recombination (Bardhan, 2010; Zamariola et al., 2014). They also have a role in centromere coupling, a mechanism by which non-homologous centromeres pair during prophase I in HR-defective mutants (Tsubouchi and Roeder, 2005) and in bouquet formation, the clustering of telomeres anchored to the nuclear envelope at early meiotic stages (Golubovskaya et al., 2006; Storlazzi et al., 2008).

\section{CONCLUSION}

The establishment of chromatid cohesion is crucial for ensuring accurate chromosome dynamics throughout the cell cycle. In plant cells, it is also essential for the development of embryos and seeds and the ability of plants to deal with DNA damage caused by ionizing radiation and faulty DNA replication. During meiosis, cohesin forms a platform for the assembly of the SC, plays an essential role in the exchange between homologous chromosomes and ensures their correct segregation at anaphase I. The regulation of meiotic and mitotic processes has a far-reaching effect on the survival and propagation of a species. Also, for agricultural applications,

\section{REFERENCES}

Almedawar, S., Colomina, N., Bermúdez-López, M., Pociño-Merino, I., and Torres-Rosell, J. (2012). A SUMO-dependent step during establishment of sister chromatid cohesion. Curr. Biol. 22, 1576-1581. doi: 10.1016/j.cub.2012.06.046

Anderson, D. E., Losada, A., Erickson, H. P., and Hirano, T. (2002). Condensin and cohesin display different arm conformations with characteristic hinge angles. J. Cell Biol. 156, 419-424. doi: 10.1083/jcb.200111002

Andrews, E. A., Palecek, J., Sergeant, J., Taylor, E., Lehmann, A. R., and Watts, F. Z. (2005). Nse2, a component of the Smc5-6 complex, is a SUMO ligase required for the response to DNA damage. Mol. Cell. Biol. 25, 185-196. doi: 10.1128/MCB.25.1.185-196.2005

Arumugam, P., Gruber, S., Tanaka, K., Haering, C. H., Mechtler, K., and Nasmyth, K. (2003). ATP hydrolysis Is required for cohesin's association with chromosomes. Curr. Biol. 13, 1941-1953. doi: 10.1016/j.cub.2003.10.036

Bai, X., Peirson, B. N., Dong, F., Xue, C., and Makaroff, C. A. (1999). Isolation and characterization of SYN1, a RAD21-like gene essential for meiosis in Arabidopsis. Plant Cell 11, 417-430. doi: 10.1105/tpc.11.3.417

Bardhan, A. (2010). Many functions of the meiotic cohesin. Chromosom. Res. 18, 909-924. doi: 10.1007/s10577-010-9169-0

Bhatt, A. M., Lister, C., Page, T., Fransz, P., Findlay, K., Jones, G. H., et al. (1999). The DIF1 gene of Arabidopsis is required for meiotic chromosome segregation the study and characterization of genes involved in the establishment of cohesion has potential to enhance the long-term survival, reproduction and adaptation of crops under adverse environmental conditions, including increased UV radiation and the presence of genotoxic agents in soil and water. In addition, cohesin manipulation could be an useful tool to generate clonal seeds by apomixis, a type of asexual reproduction that avoids meiosis. Further work is needed to continue the characterization of plant cohesin complexes, the mechanics of its regulation and to explore its potential application for plant breeding.

\section{AUTHOR CONTRIBUTIONS}

All authors listed, have made substantial, direct and intellectual contribution to the work, and approved it for publication.

\section{FUNDING}

The research on cohesion in the Makaroff laboratory is supported by grant no. MCB0718191 from the US National Science Foundation. Research at the Bolaños-Villegas laboratory is supported by intramural grants from the University of Costa Rica. Research at the Pradillo laboratory is supported by the Marie Curie Initial Training Network (ITN) COMREC (grant no. 606956) from the European Union and the Ministerio de Economía y Competitividad of Spain (grant no. AGL201567349-P).

\section{ACKNOWLEDGMENTS}

We thank Laura Smales at BioMedEditing (Toronto) for language editing, and Ernesto Bolanos-Villegas for image editing. We also thank reviewers for their helpful comments.

and belongs to the REC8/RAD21 cohesin gene family. Plant J. 19, 463-472. doi: 10.1046/j.1365-313X.1999.00548.x

Birot, A., Eguienta, K., Vazquez, S., Claverol, S., Bonneu, M., Ekwall, K., et al. (2017). A second Wpll anti-cohesion pathway requires dephosphorylation of fission yeast kleisin Rad21 by PP4. EMBO J. doi: 10.15252/embj.201696050 [Epub ahead of print].

Blat, Y., and Kleckner, N. (1999). Cohesins bind to preferential sites along yeast chromosome III, with differential regulation along arms versus the centric region. Cell 98, 249-259. doi: 10.1016/S0092-8674(00)81019-3

Bolaños-Villegas, P., and Jauh, G.-Y. (2015). Reduced activity of Arabidopsis chromosome-cohesion regulator gene CTF7/ECO1 alters cytosine methylation status and retrotransposon expression. Plant Signal. Behav. 10:e1013794. doi: 10.1080/15592324.2015.1013794

Bolaños-Villegas, P., Yang, X., Wang, H.-J., Juan, C.-T., Chuang, M.-H., Makaroff, C. A., et al. (2013). Arabidopsis CHROMOSOME TRANSMISSION FIDELITY 7 (AtCTF7/ECO1) is required for DNA repair, mitosis and meiosis. Plant J. 75, 927-940. doi: 10.1111/tpj.12261

Brough, R., Bajrami, I., Vatcheva, R., Natrajan, R., Reis-Filho, J. S., Lord, C. J., et al. (2012). APRIN is a cell cycle specific BRCA2-interacting protein required for genome integrity and a predictor of outcome after chemotherapy in breast cancer. EMBO J. 31, 1160-1176. doi: 10.1038/emboj. 2011.490 
Cai, X., Dong, F., Edelmann, R. E., and Makaroff, C. A. (2003). The Arabidopsis SYN1 cohesin protein is required for sister chromatid arm cohesion and homologous chromosome pairing. J. Cell Sci. 116, 2999-3007. doi: 10.1242/jcs. 00601

Chan, K.-L., Gligoris, T., Upcher, W., Kato, Y., Shirahige, K., Nasmyth, K., et al. (2013). Pds5 promotes and protects cohesin acetylation. Proc. Natl. Acad. Sci. U.S.A. 110, 13020-13025. doi: 10.1073/pnas.1306900110

Chatterjee, A., Zakian, S., Hu, X.-W., and Singleton, M. R. (2013). Structural insights into the regulation of cohesion establishment by Wpl1. EMBO J. 32, 677-687. doi: 10.1038/emboj.2013.16

Che, L., Tang, D., Wang, K., Wang, M., Zhu, K., Yu, H., et al. (2011). OsAM1 is required for leptotene-zygotene transition in rice. Cell Res. 21, 654-665. doi: $10.1038 / \mathrm{cr} .2011 .7$

Chelysheva, L., Diallo, S., Vezon, D., Gendrot, G., Vrielynck, N., Belcram, K., et al. (2005). AtREC8 and AtSCC3 are essential to the monopolar orientation of the kinetochores during meiosis. J. Cell Sci. 118, 4621-4632. doi: 10.1242/jcs.02583

Chen, Z., McCrosky, S., Guo, W., Li, H., and Gerton, J. L. (2012). A genetic screen to discover pathways affecting cohesin function in Schizosaccharomyces pombe identifies chromatin effectors. G3 2, 1161-1168. doi: 10.1534/g3.112.003327

Ciosk, R., Shirayama, M., Shevchenko, A., Tanaka, T., Toth, A., Shevchenko, A., et al. (2000). Cohesin's binding to chromosomes depends on a separate complex consisting of Scc2 and Scc4 proteins. Mol. Cell 5, 243-254. doi: 10.1016/S10972765(00)80420-7

Cortés-Ledesma, F., and Aguilera, A. (2006). Double-strand breaks arising by replication through a nick are repaired by cohesin-dependent sister-chromatid exchange. EMBO Rep. 7, 919-926. doi: 10.1038/sj.embor.7400774

Cromer, L., Jolivet, S., Horlow, C., Chelysheva, L., Heyman, J., De Jaeger, G., et al. (2013). Centromeric cohesion is protected twice at meiosis, by SHUGOSHINs at anaphase $\mathrm{i}$ and by PATRONUS at interkinesis. Curr. Biol. 23, 2090-2099. doi: 10.1016/j.cub.2013.08.036

Cunningham, M. D., Gause, M., Cheng, Y., Noyes, A., Dorsett, D., Kennison, J. A., et al. (2012). Wapl antagonizes cohesin binding and promotes Polycomb-group silencing in Drosophila. Development 139, 4172-4179. doi: 10.1242/dev.084566

da Costa-Nunes, J. A., Bhatt, A. M., O’Shea, S., West, C. E., Bray, C. M., Grossniklaus, U., et al. (2006). Characterization of the three Arabidopsis thaliana RAD21 cohesins reveals differential responses to ionizing radiation. J. Exp. Bot. 57, 971-983. doi: 10.1093/jxb/erj083

da Costa-Nunes, J. A., Capitão, C., Kozak, J., Costa-Nunes, P., Ducasa, G. M., Pontes, O., et al. (2014). The AtRAD21.1 and AtRAD21.3 Arabidopsis cohesins play a synergistic role in somatic DNA double strand break damage repair. BMC Plant Biol. 14:353. doi: 10.1186/s12870-014-0353-9

Dai, J., Sullivan, B. A., and Higgins, J. M. G. (2006). Regulation of mitotic chromosome cohesion by Haspin and Aurora B. Dev. Cell 11, 741-750. doi: 10.1016/j.devcel.2006.09.018

D’Ambrosio, C., Schmidt, C. K., Katou, Y., Kelly, G., Itoh, T., Shirahige, K., et al. (2008). Identification of cis-acting sites for condensin loading onto budding yeast chromosomes. Genes Dev. 22, 2215-2227. doi: 10.1101/gad. 1675708

De, K., Sterle, L., Krueger, L., Yang, X., and Makaroff, C. A. (2014). Arabidopsis thaliana WAPL is essential for the prophase removal of cohesin during meiosis. PLoS Genet. 10:e1004497. doi: 10.1371/journal.pgen.1004497

De, K., Villegas, P. B., Mitra, S., Yang, X., Homan, G., Jauh, G.-Y., et al. (2016). The opposing actions of Arabidopsis CTF7 and WAPL1/2: differences in mitotic and meiotic cells. Plant Cell 28, 521-536. doi: 10.1105/tpc.15.00781

Dong, F., Cai, X., and Makaroff, C. A. (2001). Cloning and characterization of two Arabidopsis genes that belong to the RAD21/REC8 family of chromosome cohesin proteins. Gene 271, 99-108.

Eng, T., Guacci, V., and Koshland, D. (2015). Interallelic complementation provides functional evidence for cohesin-cohesin interactions on DNA. Mol. Biol. Cell 26, 4224-4235. doi: 10.1091/mbc.E15-06-0331

Fernius, J., Nerusheva, O. O., Galander, S., Alves, F. D. L., Rappsilber, J., and Marston, A. L. (2013). Cohesin-dependent association of Scc2/4 with the centromere initiates pericentromeric cohesion establishment. Curr. Biol. 23, 599-606. doi: 10.1016/j.cub.2013.02.022

Gelot, C., Guirouilh-Barbat, J., Le Guen, T., Dardillac, E., Chailleux, C., Canitrot, Y., et al. (2016). The cohesin complex prevents the end joining of distant DNA double-strand ends. Mol. Cell 61, 15-26. doi: 10.1016/j.molcel. 2015.11.002
Gillespie, P. J., and Hirano, T. (2004). Scc2 couples replication licensing to sister chromatid cohesion in Xenopus egg extracts. Curr. Biol. 14, 1598-1603. doi: 10.1016/j.cub.2004.07.053

Gligoris, T., and Löwe, J. (2016). Structural insights into ring formation of cohesin and related SMC complexes. Trends Cell Biol. 26, 680-693. doi: 10.1016/j.tcb. 2016.04.002

Glynn, E. F., Megee, P. C., Yu, H. G., Mistrot, C., Unal, E., Koshland, D. E., et al. (2004). Genome-wide mapping of the cohesin complex in the yeast Saccharomyces cerevisiae. PLoS Biol. 2:e259. doi: 10.1371/journal.pbio.0020259

Golubovskaya, I. N., Hamant, O., Timofejeva, L., Wang, C.-J. R., Braun, D., Meeley, R., et al. (2006). Alleles of afd1 dissect REC8 functions during meiotic prophase I. J. Cell Sci. 119, 3306-3315. doi: 10.1242/jcs.03054

Gruber, S., Arumugam, P., Katou, Y., Kuglitsch, D., Helmhart, W., Shirahige, K., et al. (2006). Evidence that loading of cohesin onto chromosomes involves opening of its SMC hinge. Cell 127, 523-537. doi: 10.1016/j.cell.2006.08.048

Gruber, S., Haering, C. H., and Nasmyth, K. (2003). Chromosomal cohesin forms a ring. Cell 112, 765-777.

Guacci, V., Koshland, D., and Strunnikov, A. (1997). A direct link between sister chromatid cohesion and chromosome condensation revealed through the analysis of MCD1 in S. cerevisiae. Cell 91, 47-57. doi: 10.1016/S0092-8674(01) 80008-8

Haering, C. H., Farcas, A.-M., Arumugam, P., Metson, J., and Nasmyth, K. (2008). The cohesin ring concatenates sister DNA molecules. Nature 454, 297-301. doi: $10.1038 /$ nature 07098

Haering, C. H., Löwe, J., Hochwagen, A., and Nasmyth, K. (2002). Molecular architecture of SMC proteins and the yeast cohesin complex. Mol. Cell 9, 773-788. doi: 10.1016/S1097-2765(02)00515-4

Hakimi, M.-A., Bochar, D. A., Schmiesing, J. A., Dong, Y., Barak, O. G., Speicher, D. W., et al. (2002). A chromatin remodelling complex that loads cohesin onto human chromosomes. Nature 418, 994-998. doi: 10.1038/nature 01024

Hauf, S., Waizenegger, I. C., and Peters, J. M. (2001). Cohesin cleavage by separase required for anaphase and cytokinesis in human cells. Science 293, 1320-1323. doi: $10.1126 /$ science. 1061376

Hirano, T. (2006). At the heart of the chromosome: SMC proteins in action. Nat. Rev. Mol. Cell Biol. 7, 311-322. doi: 10.1038/nrm1909

Hirano, T. (2012). Condensins: universal organizers of chromosomes with diverse functions. Genes Dev. 26, 1659-1678. doi: 10.1101/gad.194746.112

Hou, F., and Zou, H. (2005). Two human orthologues of Ecol/Ctf7 acetyltransferases are both required for proper sister-chromatid cohesion. Mol. Biol. Cell 16, 3908-3918. doi: 10.1091/mbc.E04

Hu, B., Itoh, T., Mishra, A., Katoh, Y., Chan, K. L., Upcher, W., et al. (2011). ATP hydrolysis is required for relocating cohesin from sites occupied by its Scc2/4 loading complex. Curr. Biol. 21, 12-24. doi: 10.1016/j.cub.2010. 12.004

Huang, J., Hsu, J. M., and Laurent, B. C. (2004). The RSC nucleosome-remodeling complex is required for cohesin's association with chromosome arms. Mol. Cell 13, 739-750.

Jensen, S., Segal, M., Clarke, D. J., and Reed, S. I. (2001). A novel role of the budding yeast separin Esp1 in anaphase spindle elongation: evidence that proper spindle association of Esp1 is regulated by Pds1. J. Cell Biol. 152, 27-40. doi: 10.1083/ jcb.152.1.27

Jiang, L., Xia, M., Strittmatter, L. I., and Makaroff, C. A. (2007). The Arabidopsis cohesin protein SYN3 localizes to the nucleolus and is essential for gametogenesis. Plant J. 50, 1020-1034. doi: 10.1111/j.1365-313X.2007.03106.x

Jiang, L., Yuan, L., Xia, M., and Makaroff, C. A. (2010). Proper levels of the Arabidopsis cohesion establishment factor CTF7 are essential for embryo and megagametophyte, but not endosperm, development. Plant Physiol. 154, 820-832. doi: 10.1104/pp.110.157560

Kitajima, T. S., Kawashima, S. A., and Watanabe, Y. (2004). The conserved kinetochore protein shugoshin protects centromeric cohesion during meiosis. Nature 427, 510-517. doi: 10.1038/nature02312

Klebanow, L. R., Peshel, E. C., Schuster, A. T., De, K., Sarvepalli, K., Lemieux, M. E., et al. (2016). Drosophila condensin II subunit, chromosome associated proteinD3, regulates cell fate determination through non-cell autonomous signaling. Development 143, 2791-2802. doi: 10.1242/dev.133686

Klein, F., Mahr, P., Galova, M., Buonomo, S. B. C., Michaelis, C., Nairz, K., et al. (1999). A central role for cohesins in sister chromatid cohesion, formation 
of axial elements, and recombination during yeast meiosis. Cell 98, 91-103. doi: 10.1016/S0092-8674(00)80609-1

Kueng, S., Hegemann, B., Peters, B. H., Lipp, J. J., Schleiffer, A., Mechtler, K., et al. (2006). Wapl controls the dynamic association of cohesin with chromatin. Cell 127, 955-967. doi: 10.1016/j.cell.2006.09.040

Lam, W. S., Yang, X., and Makaroff, C. A. (2005). Characterization of Arabidopsis thaliana SMC1 and SMC3: evidence that AtSMC3 may function beyond chromosome cohesion. J. Cell Sci. 118, 3037-3048. doi: 10.1242/jcs.02443

Lengronne, A., Katou, Y., Mori, S., Yokobayashi, S., Kelly, G. P., Itoh, T., et al. (2004). Cohesin relocation from sites of chromosomal loading to places of convergent transcription. Nature 430, 573-578. doi: 10.1038/nature02742

Lengronne, A., McIntyre, J., Katou, Y., Kanoh, Y., Hopfner, K. P., Shirahige, K., et al. (2006). Establishment of sister chromatid cohesion at the S. cerevisiae replication fork. Mol. Cell 23, 787-799. doi: 10.1016/j.molcel.2006.08.018

Lhuissier, F. G. P., Offenberg, H. H., Wittich, P. E., Vischer, N. O. E., and Heyting, C. (2007). The mismatch repair protein MLH1 marks a subset of strongly interfering crossovers in tomato. Plant Cell 19, 862-876. doi: 10.1105/ tpc. 106.049106

Liu, C. M., McElver, J., Tzafrir, I., Joosen, R., Wittich, P., Patton, D., et al. (2002). Condensin and cohesin knockouts in Arabidopsis exhibit a titan seed phenotype. Plant J. 29, 405-415. doi: 10.1046/j.1365-313x.2002.01224.x

Liu, D., and Makaroff, C. A. (2015). Overexpression of a truncated CTF7 construct leads to pleiotropic defects in reproduction and vegetative growth in Arabidopsis. BMC Plant Biol 15:74. doi: 10.1186/s12870-015-0452-2

Liu, Z., and Makaroff, C. A. (2006). Arabidopsis separase AESP is essential for embryo development and the release of cohesin during meiosis. Plant Cell 18, 1213-1225. doi: $10.1105 /$ tpc. 105.036913

Lopez-Serra, L., Lengronne, A., Borges, V., Kelly, G., and Uhlmann, F. (2013). Budding yeast Wapl controls sister chromatid cohesion maintenance and chromosome condensation. Curr. Biol. 23, 64-69. doi: 10.1016/j.cub.2012. 11.030

Losada, A., Hirano, M., and Hirano, T. (2002). Cohesin release is required for sister chromatid resolution, but not for condensin-mediated compaction, at the onset of mitosis. Genes Dev. 16, 3004-3016. doi: 10.1101/gad.249202

Mayer, M. L., Gygi, S. P., Aebersold, R., and Hieter, P. (2001). Identification of RFC (Ctf18p, Ctf8p, Dcclp): an alternative RFC complex required for sister chromatid cohesion in S. cerevisiae. Mol. Cell 7, 959-970. doi: 10.1016/S10972765(01)00254-4

Mayer, M. L., Pot, I., Chang, M., Xu, H., Aneliunas, V., Kwok, T., et al. (2004). Identification of protein complexes required for efficient sister chromatid cohesion. Mol. Biol. Cell 15, 1736-1745. doi: 10.1091/mbc.E03-08-0619

McAleenan, A., Clemente-Blanco, A., Cordon-Preciado, V., Sen, N., Esteras, M., Jarmuz, A., et al. (2013). Post-replicative repair involves separase-dependent removal of the kleisin subunit of cohesin. Nature 493, 250-254. doi: 10.1038/ nature 11630

Mehta, G. D., Kumar, R., Srivastava, S., and Ghosh, S. K. (2013). Cohesin: functions beyond sister chromatid cohesion. FEBS Lett. 587, 2299-2312. doi: 10.1016/j. febslet.2013.06.035

Mengiste, T., Revenkova, E., Bechtold, N., and Paszkowski, J. (1999). An SMC-like protein is required for efficient homologous recombination in arabidopsis. EMBO J. 18, 4505-4512. doi: 10.1093/emboj/18.16.4505

Mercier, R., Armstrong, S., Horlow, C., Jackson, N., Makaroff, C., Vezon, D., et al. (2003). The meiotic protein SWI1 is required for axial element formation and recombination initiation in Arabidopsis. Development 130, 3309-3318. doi: $10.1242 /$ dev. 00550

Mercier, R., Grelon, M., Vezon, D., Horlow, C., and Pelletier, G. (2001). How to characterize meiotic functions in plants? Biochimie 83, 1023-1028. doi: 10.1016/ S0300-9084(01)01348-7

Milutinovich, M., Ünal, E., Ward, C., Skibbens, R. V., and Koshland, D. (2007). A multi-step pathway for the establishment of sister chromatid cohesion. PLoS Genet. 3:e12. doi: 10.1371/journal.pgen.0030012

Minina, E. A., Reza, S. H., Gutierrez-Beltran, E., Elander, P. H., Bozhkov, P. V., and Moschou, P. N. (2017). Arabidopsis homologue of Scc4/MAU2 is essential for plant embryogenesis. J. Cell Sci. 130, 1051-1063. doi: 10.1242/jcs.196865

Moldovan, G. L., Pfander, B., and Jentsch, S. (2006). PCNA controls establishment of sister chromatid cohesion during S phase. Mol. Cell 23, 723-732. doi: 10.1016/j.molcel.2006.07.007
Musacchio, A., and Salmon, E. D. (2007). The spindle-assembly checkpoint in space and time. Nat. Rev. Mol. Cell Biol. 8, 379-393. doi: 10.1038/nrm2163

Nasmyth, K. (2000). Splitting the chromosome: cutting the ties that bind sister chromatids. Science 288, 1379-1384. doi: 10.1126/science.288.5470.1379

Nasmyth, K., and Haering, C. H. (2009). Cohesin: its roles and mechanisms. Annu. Rev. Genet. 43, 525-558. doi: 10.1146/annurev-genet-102108-134233

Nishiyama, T., Ladurner, R., Schmitz, J., Kreidl, E., Schleiffer, A., Bhaskara, V., et al. (2010). Sororin mediates sister chromatid cohesion by antagonizing Wapl. Cell 143, 737-749. doi: 10.1016/j.cell.2010.10.031

Nonaka, N., Kitajima, T., Yokobayashi, S., Xiao, G., Yamamoto, M., Grewal, S. I. S., et al. (2002). Recruitment of cohesin to heterochromatic regions by Swi6/HP1 in fission yeast. Nat. Cell Biol. 4, 89-93. doi: 10.1038/ncb739

Onn, I., Heidinger-Pauli, J. M., Guacci, V., Unal, E., and Koshland, D. E. (2008). Sister chromatid cohesion: a simple concept with a complex reality. Annu. Rev. Cell Dev. Biol. 24, 105-129. doi: 10.1146/annurev.cellbio.24.110707.175350

Ono, T., Losada, A., Hirano, M., Myers, M. P., Neuwald, A. F., and Hirano, T. (2003). Differential contributions of condensin I and condensin II to mitotic chromosome architecture in vertebrate cells. Cell 115, 109-121. doi: 10.1016/ S0092-8674(03)00724-4

Ouyang, Z., Zheng, G., Song, J., Borek, D. M., Otwinowski, Z., Brautigam, C. A., et al. (2013). Structure of the human cohesin inhibitor Wapl. Proc. Natl. Acad. Sci. U.S.A. 110, 11355-11360. doi: 10.1073/pnas.1304594110

Palecek, J., Vidot, S., Feng, M., Doherty, A. J., and Lehmann, A. R. (2006). The Smc5-Smc6 DNA repair complex: bridging of the Smc5-Smc6 heads by the kleisin, nse4, and non-kleisin subunits. J. Biol. Chem. 281, 36952-36959. doi: 10.1074/jbc.M608004200

Pawlowski, W., Wang, C., Golubovskaya, I. N., Szymaniak, J. M., Shi, L. Hamant, O., et al. (2009). Maize AMEIOTIC1 is essential for multiple early meiotic processes and likely required for the initiation of meiosis. Proc. Natl. Acad. Sci. U.S.A. 106, 3603-3608. doi: 10.1073/pnas.0810115106

Pebernard, S., McDonald, H. W., Pavlova, Y., Yates, J. R. III, and Boddy, M. N. (2004). Nse1, Nse2, and a novel subunit of the Smc5-Smc6 complex, Nse3, play a crucial role in meiosis. Mol. Biol. Cell 15, 4866-4876. doi: 10.1091/mbc. E04-05-6

Peirson, B. N., Bowling, S. E., and Makaroff, C. A. (1997). A defect in synapsis causes male sterility in a T-DNA-tagged Arabidopsis thaliana mutant. Plant J. 11, 659-669. doi: 10.1046/j.1365-313X.1997.11040659.x

Peters, J.-M., and Nishiyama, T. (2012). Sister chromatid cohesion. Cold Spring Harb. Perspect. Biol. 4:a011130. doi: 10.1101/cshperspect.a011130

Petronczki, M., Chwalla, B., Siomos, M. F., Yokobayashi, S., Helmhart, W., Deutschbauer, A. M., et al. (2004). Sister-chromatid cohesion mediated by the alternative RF-CCtf18/Dccl/Ctf8, the helicase Chl1 and the polymerase-alphaassociated protein $\mathrm{Ctf} 4$ is essential for chromatid disjunction during meiosis II. J. Cell Sci. 117, 3547-3559. doi: 10.1242/jcs.01231

Pradillo, M., Knoll, A., Oliver, C., Varas, J., Corredor, E., Puchta, H., et al. (2015). Involvement of the cohesin cofactor PDS5 (SPO76) during meiosis and DNA repair in Arabidopsis thaliana. Front. Plant Sci. 6:1034. doi: 10.3389/fpls.2015. 01034

Prieto, I., Suja, J. A., Pezzi, N., Kremer, L., Martínez-A, C., Rufas, J. S., et al. (2001). Mammalian STAG3 is a cohesin specific to sister chromatid arms in meiosis I. Nat. Cell Biol. 3, 761-766. doi: 10.1038/35087082

Qi, Y., Zhang, Y., Zhang, F., Baller, J. A., Cleland, S. C., Ryu, Y., et al. (2013). Increasing frequencies of site-specific mutagenesis and gene targeting in Arabidopsis by manipulating DNA repair pathways. Genome Res. 23, 547-554. doi: 10.1101 /gr.145557.112

Rankin, S., Ayad, N. G., and Kirschner, M. W. (2005). Sororin, a substrate of the anaphase- promoting complex, is required for sister chromatid cohesion in vertebrates. Mol. Cell 18, 185-200. doi: 10.1016/j.molcel.2005.03.017

Revenkova, E., Eijpe, M., Heyting, C., Gross, B., and Jessberger, R. (2001). Novel meiosis-specific isoform of mammalian SMC1. Mol. Cell. Biol. 21, 6984-6998. doi: 10.1128/MCB.21.20.6984-6998.2001

Ritchie, K., Seah, C., Moulin, J., Isaac, C., Dick, F., and Bérubé, N. G. (2008). Loss of ATRX leads to chromosome cohesion and congression defects. J. Cell Biol. 180, 315-324. doi: 10.1083/jcb.200706083

Rivera, T., and Losada, A. (2009). Shugoshin regulates cohesion by driving relocalization of PP2A in Xenopus extracts. Chromosoma 118, 223-233. doi: 10.1007/s00412-008-0190-4 
Rivera, T., and Losada, A. (2010). Recycling cohesin rings by deacetylation. Mol. Cell 39, 657-659. doi: 10.1016/j.molcel.2010.08.032

Rolef Ben-Shahar, T., Heeger, S., Lehane, C., East, P., Flynn, H., Skehel, M., et al. (2008). Ecol-dependent cohesin acetylation during establishment of sister chromatid cohesion. Science 321, 563-566. doi: 10.1126/science.1157774

Rowland, B. D., Roig, M. B., Nishino, T., Kurze, A., Uluocak, P., Mishra, A., et al. (2009). Building sister chromatid cohesion: Smc3 acetylation counteracts an antiestablishment activity. Mol. Cell 33, 763-774. doi: 10.1016/j.molcel.2009. 02.028

Sakamoto, T., Inui, Y. T., Uraguchi, S., Yoshizumi, T., Matsunaga, S., Mastui, M., et al. (2011). Condensin II alleviates DNA damage and is essential for tolerance of boron overload stress in Arabidopsis. Plant Cell 23, 3533-3546. doi: 10.1105/ tpc.111.086314

Schmidt, C. K., Brookes, N., and Uhlmann, F. (2009). Conserved features of cohesin binding along fission yeast chromosomes. Genome Biol. 10:R52. doi: 10.1186/gb-2009-10-5-r52

Schmitz, J., Watrin, E., Lénárt, P., Mechtler, K., and Peters, J. M. (2007). Sororin is required for stable binding of cohesin to chromatin and for sister chromatid cohesion in interphase. Curr. Biol. 17, 630-636. doi: 10.1016/j.cub.2007.02.029

Schubert, V. (2009). SMC proteins and their multiple functions in higher plants. Cytogenet. Genome Res. 124, 202-214. doi: 10.1159/000218126

Schubert, V., Lermontova, I., and Schubert, I. (2013). The Arabidopsis CAP-D proteins are required for correct chromatin organisation, growth and fertility. Chromosoma 122, 517-533. doi: 10.1007/s00412-013-0424-y

Sebastian, J., Ravi, M., Andreuzza, S., Panoli, A. P., Marimuthu, M. P. A., and Siddiqi, I. (2009). The plant adherin AtSCC2 is required for embryogenesis and sister-chromatid cohesion during meiosis in Arabidopsis. Plant J. 59, 1-13. doi: 10.1111/j.1365-313X.2009.03845.x

Seitan, V. C., Banks, P., Laval, S., Majid, N. A., Dorsett, D., Rana, A., et al. (2006). Metazoan Scc4 homologs link sister chromatid cohesion to cell and axon migration guidance. PLoS Biol. 4:e242. doi: 10.1371/journal.pbio.0040242

Singh, D. K., Andreuzza, S., Panoli, A. P., and Siddiqi, I. (2013). AtCTF7 is required for establishment of sister chromatid cohesion and association of cohesin with chromatin during meiosis in Arabidopsis. BMC Plant Biol. 13:117. doi: 10.1186/ 1471-2229-13-7

Sjögren, C., and Nasmyth, K. (2001). Sister chromatid cohesion is required for postreplicative double-strand break repair in Saccharomyces cerevisiae. Curr. Biol. 11, 991-995. doi: 10.1016/S0960-9822(01)00271-8

Skibbens, R. V., Corson, L. B., Koshland, D., and Hieter, P. (1999). Ctf7p is essential for sister chromatid cohesion and links mitotic chromosome structure to the DNA replication machinery. Genes Dev. 13, 307-319. doi: 10.1101/gad.13.3.307

Stemmann, O., Zou, H., Gerber, S. A., Gygi, S. P., and Kirschner, M. W. (2001). Dual inhibition of sister chromatid separation at metaphase. Cell 107, 715-726. doi: 10.1016/S0092-8674(01)00603-1

Storlazzi, A., Tesse, S., Ruprich-Robert, G., Gargano, S., Pöggeler, S., Kleckner, N., et al. (2008). Coupling meiotic chromosome axis integrity to recombination. Genes Dev. 22, 796-809. doi: 10.1101/gad.459308

Ström, L., Karlsson, C., Lindroos, H. B., Wedahl, S., Katou, Y., Shirahige, K., et al. (2007). Postreplicative formation of cohesion is required for repair and induced by a single DNA break. Science 317, 242-245. doi: 10.1126/science.1140649

Sumara, I., Vorlaufer, E., Gieffers, C., Peters, B. H., and Peters, J. M. (2000). Characterization of vertebrate cohesin complexes and their regulation in prophase. J. Cell Biol. 151, 749-761. doi: 10.1083/jcb.151.4.749

Sutani, T., Kawaguchi, T., Kanno, R., Itoh, T., and Shirahige, K. (2009). Budding yeast Wpl1(Rad61)-Pds5 complex counteracts sister chromatid cohesionestablishing reaction. Curr. Biol. 19, 492-497. doi: 10.1016/j.cub.2009.01.062

Takahashi, T. S., Basu, A., Bermudez, V., Hurwitz, J., and Walter, J. C. (2008). Cdc7Drf1 kinase links chromosome cohesion to the initiation of DNA replication in Xenopus egg extracts. Genes Dev. 22, 1894-1905. doi: 10.1101/gad.1683308

Takahashi, T. S., Yiu, P., Chou, M. F., Gygi, S., and Walter, J. C. (2004). Recruitment of Xenopus Scc2 and cohesin to chromatin requires the pre-replication complex. Nat. Cell Biol. 6, 991-996. doi: 10.1038/ncb1177

Tang, Z., Shu, H., Qi, W., Mahmood, N. A., Mumby, M. C., and Yu, H. (2006). PP2A Is required for centromeric localization of Sgol and proper chromosome segregation. Dev. Cell 10, 575-585. doi: 10.1016/j.devcel.2006.03.010

Tapia-Alveal, C., Lin, S.-J., and O'Connell, M. J. (2014). Functional interplay between cohesin and Smc5/6 complexes. Chromosoma 123, 437-445. doi: 10.1007/s00412-014-0474-9
Tomonaga, T., Nagao, K., Kawasaki, Y., Furuya, K., Murakaini, A., Morishita, J., et al. (2000). Characterization of fission yeast cohesin: essential anaphase proteolysis of Rad21 phosphorylated in the S phase. Genes Dev. 14, 2757-2770. doi: $10.1101 /$ gad. 832000

Tóth, A., Ciosk, R., Uhlmann, F., Galova, M., Schleiffer, A., and Nasmyth, K. (1999). Yeast cohesin complex requires a conserved protein, Ecolp(Ctf7), to establish cohesion between sister chromatids during DNA replication. Genes Dev. 13, 320-333. doi: 10.1101/gad.13.3.320

Toyoda, Y., Furuya, K., Goshima, G., Nagao, K., Takahashi, K., and Yanagida, M. (2002). Requirement of chromatid cohesion proteins Rad21/Sccl and Mis4/Scc2 for normal spindle-kinetochore interaction in fission yeast. Curr. Biol. 12, 347-358. doi: 10.1016/S0960-9822(02)00692-9

Tsubouchi, T., and Roeder, G. S. (2005). A synaptonemal complex protein promotes homology-independent centromere coupling. Science 308, 870-873. doi: $10.1126 /$ science. 1108283

Uhlmann, F., Lottspeich, F., and Nasmyth, K. (1999). Sister-chromatid separation at anaphase onset is promoted by cleavage of the cohesin subunit Sccl. Nature 400, 37-42. doi: 10.1038/21831

Uhlmann, F., and Nasmyth, K. (1998). Cohesion between sister chromatids must be established during DNA replication. Curr. Biol. 8, 1095-1101. doi: 10.1016/ S0960-9822(98)70463-4

Unal, E., Heidinger-Pauli, J. M., Kim, W., Guacci, V., Onn, I., Gygi, S. P., et al. (2008). A molecular determinant for the establishment of sister chromatid cohesion. Science 321, 566-569. doi: 10.1126/science.1157880

Vaur, S., Feytout, A., Vazquez, S., and Javerzat, J. (2012). Pds5 promotes cohesin acetylation and stable cohesin-chromosome interaction. EMBO Rep. 13, 645-652. doi: 10.1038/embor.2012.72

Vernì, F., Gandhi, R., Goldberg, M. L., and Gatti, M. (2000). Genetic and molecular analysis of wings apart-like (wapl), a gene controlling heterochromatin organization in Drosophila melanogaster. Genetics 154, 1693-1710.

Verver, D., Zheng, Y., Speijer, D., Hoebe, R., Dekker, H. L., Repping, S., et al. (2016). Non-SMC element 2 (NSMCE2) of the SMC5/6 complex helps to resolve topological stress. Int. J. Mol. Sci. 17:1782. doi: 10.3390/ijms171 11782

Waizenegger, I. C., Hauf, S., Meinke, A., and Peters, J. M. (2000). Two distinct pathways remove mammalian cohesin from chromosome arms in prophase and from centromeres in anaphase. Cell 103, 399-410. doi: 10.1016/S0092-8674(00) 00132-X

Warren, C. D., Eckley, D. M., Lee, M. S., Hanna, J. S., Hughes, A., Peyser, B., et al. (2004). S-phase checkpoint genes safeguard high-fidelity sister chromatid cohesion. Mol. Biol. Cell 15, 1724-1735. doi: 10.1091/mbc. E03-09-7

Watanabe, K., Pacher, M., Dukowic, S., Schubert, V., Puchta, H., and Schubert, I. (2009). The STRUCTURAL MAINTENANCE OF CHROMOSOMES 5/6 complex promotes sister chromatid alignment and homologous recombination after DNA damage in Arabidopsis thaliana. Plant Cell 21, 2688-2699. doi: 10. 1105/tpc.108.060525

Watanabe, Y., and Nurse, P. (1999). Cohesin Rec8 is required for reductional chromosome segregation at meiosis. Nature 400, 461-464. doi: 10.1038/22774

Watrin, E., Schleiffer, A., Tanaka, K., Eisenhaber, F., Nasmyth, K., and Peters, J. M. (2006). Human Scc4 is required for cohesin binding to chromatin, sisterchromatid cohesion, and mitotic progression. Curr. Biol. 16, 863-874. doi: 10.1016/j.cub.2006.03.049

Weber, S. A., Gerton, J. L., Polancic, J. E., DeRisi, J. L., Koshland, D., and Megee, P. C. (2004). The kinetochore is an enhancer of pericentric cohesin binding. PLoS Biol. 2:E260. doi: 10.1371/journal.pbio.0020260

Woo, J. S., Lim, J. H., Shin, H. C., Suh, M. K., Ku, B., Lee, K. H., et al. (2009). Structural studies of a bacterial condensin complex reveal ATP-dependent disruption of intersubunit interactions. Cell 136, 85-96. doi: 10.1016/j.cell.2008. 10.050

Wu, N., Kong, X., Ji, Z., Zeng, W., Potts, P. R., Yokomori, K., et al. (2012). Scc1 sumoylation by Mms21 promotes sister chromatid recombination through counteracting Wapl. Genes Dev. 26, 1473-1485. doi: 10.1101/gad.193 615.112

Wu, S., Scheible, W.-R., Schindelasch, D., Van Den Daele, H., De Veylder, L., and Baskin, T. I. (2010). A conditional mutation in Arabidopsis thaliana separase induces chromosome non-disjunction, aberrant morphogenesis 
and cyclin B1;1 stability. Development 137, 953-961. doi: 10.1242/dev. 041939

Xu, P., Yuan, D., Liu, M., Li, C., Liu, Y., Zhang, S., et al. (2013). AtMMS21, an SMC5/6 complex subunit, is involved in stem cell niche maintenance and DNA damage responses in Arabidopsis roots. Plant Physiol. 161, 1755-1768. doi: 10.1104/pp.112.208942

Yang, X., Boateng, K. A., Strittmatter, L., Burgess, R., and Makaroff, C. A. (2009). Arabidopsis separase functions beyond the removal of sister chromatid cohesion during meiosis. Plant Physiol. 151, 323-333. doi: 10.1104/pp.109. 140699

Yuan, L., Yang, X., and Makaroff, C. A. (2011). Plant cohesins, common themes and unique roles. Curr. Protein Pept. Sci. 12, 93-104. doi: 10.2174/ 138920311795684904

Zamariola, L., De Storme, N., Tiang, C. L., Armstrong, S. J., Franklin, F. C. H., and Geelen, D. (2013). SGO1 but not SGO2 is required for maintenance of centromere cohesion in Arabidopsis thaliana meiosis. Plant Reprod. 26, 197-208. doi: 10.1007/s00497-013-0231-x

Zamariola, L., Tiang, C. L., De Storme, N., Pawlowski, W., and Geelen, D. (2014). Chromosome segregation in plant meiosis. Front. Plant Sci. 5:279. doi: 10.3389/ fpls.2014.00279

Zhang, J., Shi, X., Li, Y., Kim, B. J., Jia, J., Huang, Z., et al. (2008). Acetylation of Smc3 by Ecol is required for $\mathrm{S}$ phase sister chromatid cohesion in both human and yeast. Mol. Cell 31, 143-151. doi: 10.1016/j.molcel.2008.06.006
Zhang, L., Tao, J., Wang, S., Chong, K., and Wang, T. (2006). The rice OsRad21-4 an orthologue of yeast Rec8 protein, is required for efficient meiosis. Plant Mol. Biol. 60, 533-554. doi: 10.1007/s11103-005-4922-z

Zhao, D., Yang, X., Quan, L., Timofejeva, L., Rigel, N. W., Ma, H., et al. (2006). ASK1, a SKP1 homolog, is required for nuclear reorganization, presynaptic homolog juxtaposition and the proper distribution of cohesin during meiosis in Arabidopsis. Plant Mol. Biol. 62, 99-110. doi: 10.1007/s11103-006-9006-1

Conflict of Interest Statement: The authors declare that the research was conducted in the absence of any commercial or financial relationships that could be construed as a potential conflict of interest.

The reviewer MPAM and handling Editor declared their shared affiliation, and the handling Editor states that the process nevertheless met the standards of a fair and objective review.

Copyright (c) 2017 Bolaños-Villegas, De, Pradillo, Liu and Makaroff. This is an openaccess article distributed under the terms of the Creative Commons Attribution License (CC BY). The use, distribution or reproduction in other forums is permitted, provided the original author(s) or licensor are credited and that the original publication in this journal is cited, in accordance with accepted academic practice. No use, distribution or reproduction is permitted which does not comply with these terms. 